\title{
Correlation between Early and Late Growth Characters in an Improved True Potato Seed Population
}

\author{
A. Golmirzaie ${ }^{1}$ and F. Serquen ${ }^{2}$ \\ International Potato Center, P. O. Box 5969, Lima, Peru
}

Additional index word. Solarium tuberosum

\begin{abstract}
A field experiment was conducted at two locations to determine the correlation between seedling and mature plant characters in a large potato (Solanum tuberosum) population developed for production from true potato seed. There was no significant correlation between seedling and reproductive characters, including earliness, at the two locations. Number of internodes and yield per plant were significantly correlated at Huancayo, and at San Ramon, root length and hypocotyl length had a significant correlation with the number of tubers per plant and yield per plant. Although significant, the latter correlations are not high enough to be used to predict the final behavior of genotypes by their seedling traits. Thus, it may be assumed that a certain independence between seedling and mature plant growth characters exists.
\end{abstract}

For many years the production of ware potatoes from true potato seed (TPS) has had high priority in the research carried out at the International Potato Center (CIP), Lima, Peru (Pallais, 1991).

The complex mode of genetic segregation for agronomic traits in potato, due to its autotetraploid nature (Ross, 1986), determines that, after crossing, many seedlings have to be evaluated to select the desirable genotypes. This problem increases the need for field space, manual labor, and facilities. For some characters, e.g., resistance to some diseases, the initial evaluations are done at the seedling stage, when undesirable genotypes are discarded, thus requiring the planting of fewer genotypes in the field (Anguiz and Mendoza, 1989). This procedure also could be used for agronomical and/or repro-

Received for publication 15 Aug. 1991. Accepted for publication 17 Oct. 1991. The cost of publishing this paper was defrayed in part by the payment of page charges. Under postal regulations, this paper therefore must be hereby marked advertise ment solely to indicate this fact.

'Geneticist.

${ }^{2}$ Associate Breeder. ductive traits in a breeding population if any correlation existed between selected seedling traits and those of the mature plant.

Livermore (1939) correlated seedling traits in the greenhouse and subsequent yield in the field. He found a slight association between greenhouse and field performance. He also found seedling growth of very little help in detecting yielding ability in the greenhouse or in the field. With some families, he obtained better correlation coefficients than with others, but they still were too low to permit selection at the seedling level.

Zubeldía (1963) identified a useful selec-

Table 1. Analysis of variance for potato seedling traits. San Ramón and Huancayo, 1988.

\begin{tabular}{lcccc}
\hline \hline & \multicolumn{4}{c}{ Trait $^{z}$} \\
\cline { 2 - 5 } Source & RL & HL & NI & LFI \\
\hline Locality (L) & $* *$ & $* *$ & $* *$ & $* *$ \\
Family (F) & $* *$ & $* *$ & $* *$ & $* *$ \\
L $\times$ F & $* *$ & $* *$ & $* *$ & $* *$ \\
CV (\%) & 14.96 & 16.23 & 9.95 & 19.02
\end{tabular}

${ }^{2} \mathrm{RL}=$ root length $(\mathrm{cm}) ; \mathrm{HL}=$ hypocotyl length $(\mathrm{cm}) ; \mathrm{NI}=$ number of internodes; LFI = length of first internode $(\mathrm{cm})$.

**Significant at $P<0.01$. 
Table 2. Range, mean, and SE of potato seedling traits, San Ramón and Huancayo, 1988.

\begin{tabular}{lcccc}
\hline \hline \multirow{2}{*}{$\begin{array}{l}\text { Locality and } \\
\text { statistic }\end{array}$} & RL & HL & NI & LFI \\
\cline { 2 - 5 } & & & & \\
Huancayo & & & & \\
Range & $19.3-40.0$ & $5.0-14.0$ & $3.0-16.7$ & $3.3-6.0$ \\
Mean & 27.4 & 8.3 & 8.7 & 4.7 \\
SE & 6.04 & 2.12 & 1.04 & 1.11 \\
San Ramón & & & & \\
Range & $0.53-2.83$ & $0.87-2.93$ & $1-3.2$ & $4.0-9.0$ \\
Mean & 1.5 & 1.9 & 1.4 & 6.4 \\
SE & 0.24 & 0.24 & 0.20 & 0.97 \\
\hline
\end{tabular}

${ }^{2} \mathrm{RL}=$ root length $(\mathrm{cm}) ; \mathrm{HL}=$ hypocotyl length $(\mathrm{cm}) ; \mathrm{NI}=$ number of internodes; $\mathrm{LFI}=$ length of first internode $(\mathrm{cm})$.

Table 3. Correlation coefficients of early and late potato growth characteristics, 1988.

\begin{tabular}{lrrrr}
\hline \hline & \multicolumn{4}{c}{ Trait $^{2}$} \\
\cline { 2 - 5 } Trait $^{2}$ & RL & HL & \multicolumn{1}{c}{ LFI } & \multicolumn{1}{c}{ NI } \\
\hline Huancayo & & & & \\
DFI & -0.095 & 0.060 & 0.177 & -0.081 \\
FI & 0.026 & -0.189 & 0.003 & 0.041 \\
FD & 0.023 & 0.076 & 0.023 & 0.094 \\
NFI & -0.034 & 0.010 & 0.044 & -0.032 \\
E & -0.146 & 0.012 & -0.037 & 0.016 \\
NTP & 0.093 & 0.108 & -0.186 & 0.123 \\
YP & 0.116 & 0.095 & -0.015 & $0.196^{*}$ \\
San Ramón & & & & \\
DFI & -0.163 & 0.117 & 0.079 & -0.028 \\
FI & 0.051 & -0.146 & -0.017 & 0.069 \\
FD & 0.203 & -0.096 & -0.011 & 0.125 \\
NFI & -0.011 & 0.068 & -0.042 & 0.048 \\
E & -0.118 & 0.029 & 0.042 & -0.185 \\
NTP & $-0.370^{*}$ & $0.298^{*}$ & -0.022 & -0.039 \\
YP & $-0.239^{*}$ & $0.242^{*}$ & -0.008 & 0.042 \\
\hline
\end{tabular}

${ }^{2} \mathrm{RL}=$ root length $(\mathrm{cm}) ; \mathrm{HL}=$ hypocotyl length $(\mathrm{cm}) ; \mathrm{NI}=$ number of internodes; LFI = length of first internode $(\mathrm{cm}) ; \mathrm{DFI}=$ days to flowering initiation; $\mathrm{FI}=$ flowering intensity; FD = flowering duration; NFI = number of flowers per inflorescence; $E=$ earliness; $N T P=$ number of tubers per plant; $\mathrm{YP}=$ yield per plant.

*Significant at $P<0.05$.

tion criterion for the breeding of early varieties. He found that seedlings with closed tops developed into late forms, while those with open tops generally matured early. Engel and Moller (1959) found that $80 \%$ of seedlings showing long stolons when ready to transplant from boxes to pots (second transplantation) had either early or mediumearly maturity. They used this criterion for detecting earliness in crosses of early $x$ late forms that were expected to give a high frequency of lates. Dayal et al. (1984) reported that the 1000-TPS weight may have a predictive value for the performance of seedling populations. They found positive phenotypic and genotypic correlations of 1000-TPS weight with total tuber yield, number of leaves on the main shoot, number of shoots per plant, and harvest index. Likewise, Malagamba (1987) reported that root regeneration was the factor mostly correlated to growth recovery after transplanting. In sweetpotato, MacDonald (1969) found correlations between seedlings and their vegetatively reproduced progeny and concluded that much good breeding material would be discarded if selection were exerted at the seedling stage rather than on the vegetative progeny.

The purpose of this experiment was to determine the degree of correlation between seedling [root length (RL), hypocotyl length (HL), number of internodes (NI), and length of first internode (LFI)] reproductive traits [days to flowering initiation (DFI), flowering intensity (FI), flowering duration (FD), number of flowers per inflorescence (NFI), and pollen production (PP)] and agronomic traits [earliness $(\mathrm{E})$, number of tubers per plant (NTP), and yield per plant (YP)] in an advanced TPS population.

The experiment was carried out at CIP experiment stations at Huancayo $(3280 \mathrm{~m}$ and $12^{\circ} 07 '$ S.) and at San Ramón (800 $\mathrm{m}$ and $11^{\circ} 08^{\prime}$ 'S.) in Peru. It included $\approx 32,000$ seedlings derived from 80 cross-combinations. The families were obtained by using a North Carolina II mating design with five sets and 16 clones per set. The seeds were produced in Huancayo under greenhouse conditions (14 h of illumination). Before sowing, the seeds were soaked in a solution of $1500 \mathrm{ppm}$ gibberellic acid for $24 \mathrm{~h}$. Seeds were sown in plastic trays containing a substrate made with 1 sand: 2 peat : 1 soil (by volume). We used 200 seeds per tray, in rows of 20 seeds each, to facilitate evaluation of emergence percentage. When seedlings were 3 to $5 \mathrm{~cm}$ high, they were transferred into peat pots and grown to $\approx 15$ $\mathrm{cm}$ high. The agronomic practices were done as standard for this crop. The day before transferring the seedlings into peat pots, the RL and HL were taken in a sample of 20 seedlings/family. The LFI and NI were taken the day before transplanting the seedlings into the field. The sample size was the same as that for the former traits. At this stage, the seedlings were transplanted into the field in a complete block design with three replications. Each replication had rows $12 \mathrm{~m}$ long with $0.75 \mathrm{~m}$ between rows, and a plant spacing of $0.30 \mathrm{~m}$. Each row was an experimental plot with 40 plants.

During the growing period, traits, such as DF, FD, FI, NFI, and PP, were recorded. The agronomic characters evaluated included earliness, measured 75 days after transplanting, and NTP and YP, taken at harvest. For earliness and reproductive characters (FI, FD, NFI, and PP), a scale of 1 to 9 was used: $1=$ latest and $9=$ earliest for FI and $1=$ lowest and $9=$ highest value for reproductive traits. Statistical analysis was performed according to the experimental design. Correlation analyses for seedling traits vs. agronomical and reproductive characters were performed.

The analysis of variance showed highly significant differences between localities, families, and their interactions (Table 1). The higher mean values for the characters studied were obtained in Huancayo (Table 2), presumably because the environmental conditions existing there are more favorable for potato cultivation and the population we worked with was more adapted to those conditions. The correlation coefficients also were performed for each locality (Table 3 ). The lowest association values (most near zero) were obtained for the reproductive characters. The highest values for these coefficients were obtained for RL and FD at San Ramón, but they were still not significant.

Reproductive characters are important in a program to develop genetic material for TPS purposes, because they are aimed at determining the potential of this material to be grown directly from TPS. For example, in a program of hybrid seed or open-pollinated seed, genetic material with good berry and seed production is needed. For earliness, the highest correlation coefficient obtained in Huancayo was $r=-0.146$, explaining only $2.13 \%$ of the variations in earliness caused by the differences in root length. The rest of the coefficients were close to zero, suggesting an almost complete absence of association among these characters. The same results were obtained in San Ramón for this character. Earliness is an important character in a breeding program, being one of the first traits selected at the earlier phases. For this character, it is important to find a highly correlated trait at the seedling stage to reduce the number of genotypes brought to the field. For NTP, there was no significance in correlation coefficients at Huancayo, most being close to zero. However, at San Ramón, there were significant correlation coefficients between RL and HL with NTP, explaining $13.69 \%$ and $8.88 \%$ of tubers per plant variation, respectively. The correlation with RL was negative. For YP, again there was no significant relationship with the seedling traits studied in Huancayo, except with NI. In San Ramón the correlation was significant for RL and HL, being negative for the former and positive for the latter. This means that if we select at the seedling stage, we have to take these two traits into consideration. In any case, we should consider that, although statistically significant, these correlation coefficients are still low and the degree of confidence in our selection also would be low.

These results lead us to conclude that there is a certain independence between seedling and mature plant traits. Even though the correlation coefficient for seedling traits and tuber number and yield were higher than for reproductive characters, they were not large enough to guarantee the desired response in more mature plants if selected for some traits at the seedling stage. Perhaps seedling dry weight would be an interesting trait to take 
into account. Another character to consider could be the length of stolons, which seems to be associated with earliness, although no clear-cut associations have been established.

\section{Literature Cited}

Anguiz, R. and H. Mendoza. 1989. Correlación entre la resistencia al tizón temprano (Alternaria solani) en plántulas y plantas adultas de papa. Congreso de la Asociación Latinoamericana de Fitopatología 10. Congreso ASCOLFI 29. Reunión APS-CD. Cali, Colombia. p. 114.
Dayal, T. R., M.D. Upadhya, and S.N. Chaturvedi. 1984. Correlation studies on 1000-trueseed weight, tuber yield and other morphological traits in potato (Solanum tuberosum L.) Potato Res. 27:185-188.

Engel, K.H. and K.H. Moller. 1959. Frühdiagnose auf Reifezeit an Kartoffel Sämlingen. Züchter. 29:218-220.

Livermore, J.R. 1939. Correlation of seedling performance in the greenhouse and subsequen yield in the field. Amer. Potato J. 16(2):41-43.

MacDonald. A.S. 1969. Correlations between some characters of sweet potato seedlings and their vegetatively reproduced progeny. East Afr. Agr.
Forest J. (Kenya). 34(3):315-326.

Malagamba, J.P. 1987. Differential responses to transplanting in potato seedlings. 10th Triennial Conf. Eur. Assn. Potato Res. (EAPR), Aalborg, Denmark. p. 176.

Pallais, N. 1991. True potato seed: Changing potato propagation from vegetative to sexual. HortScience 26:239-241.

Ross, H. 1986. Potato breeding: Problems and perspectives. Verlag Paul Parey, Berlin and Hamburg.

Zubeldia, A. 1963. Selection of young potato seedlings for earliness. Eur. Potato. J. 6(3):178185. 